CAMBRIDGE

New Titles from Cambridge University Press!

Causality, Probability, and Time

Samantha Kleinberg

\$99.00: Hardback: 978-1-107-02648-3: 265 pp.

\section{Data-Intensive Computing}

Architectures, Algorithms, and Applications

Edited by Ian Gorton and Deborah K. Gracio

\$70.00: Hardback: 978-0-521-19195-1: 297 pp.

\section{Forthcoming!}

\section{Excel Basics to Blackbelt}

An Accelerated Guide to Decision Support Designs Second Edition

Elliot Bendoly

Paperback: 978-1-107-62552-5

\section{Machine Learning}

The Art and Science of Algorithms that Make Sense of Data

Peter Flach

\$120.00: Hardback: 978-1-107-09639-4: 409 pp.

\$60.00: Paperback: 978-1-107-42222-3

\section{Multimodal Signal Processing}

Human Interactions in Meetings

Edited by Steve Renals, Hervé Bourlard, Jean Carletta, and Andrei Popescu-Belis

\$120.00: Hardback: 978-1-107-02229-4: 286 pp.

\section{Optimal Estimation of Parameters}

Jorma Rissanen

\$90.00: Hardback: 978-1-107-00474-0: 170 pp.

\section{Relational Knowledge Discovery}

M. E. Müller

\$99.00: Hardback: 978-0-521-19021-3: 278 pp.

\$47.00: Paperback: 978-0-521-12204-7

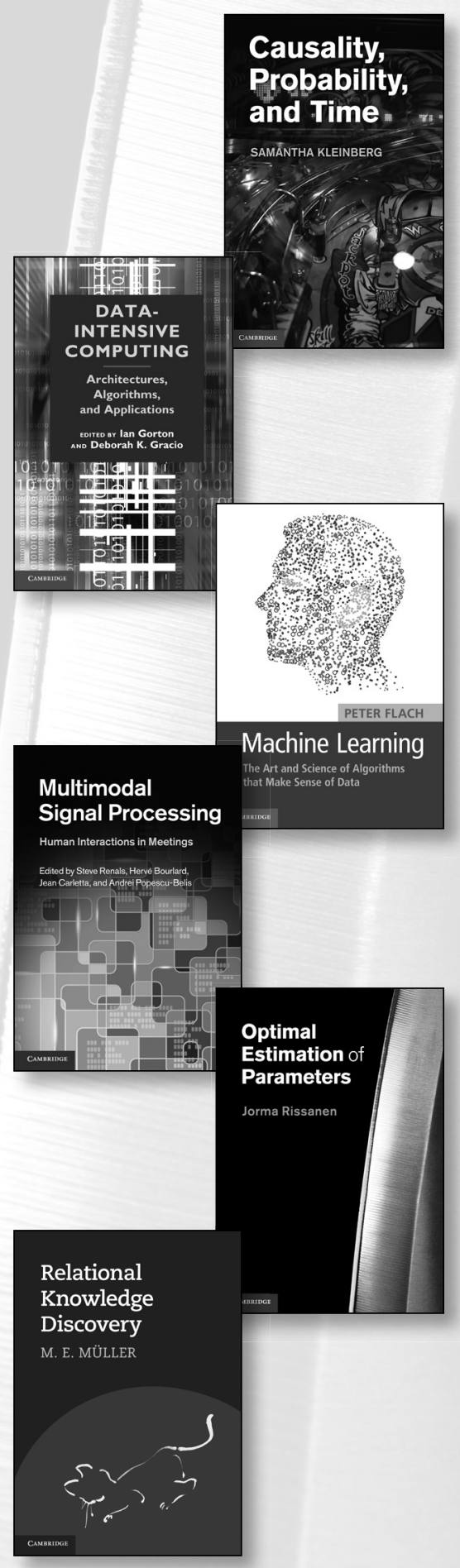

Prices subject to change.

www.cambridge.org/us/computerscience

3 @cambUP_maths

800.872 .7423 


\section{CAMBRIDGE JOURALS}

\section{Robotica}

An Official Journal of the

International Federation of Robotics

Editor-in-Chief

G. S. Chirikjian, Johns Hopkins University, USA

Robotica provides an international forum for the multidisciplinary subject of robotics and encourages developments in this important field of automation with regard to industry, education and research. It covers the many aspects of robotics, including sensory perception, software, kinematics and dynamics involved in robot design, robot task planning and description, intelligibility of skilled motion, applications of robots in the service industries, world model representation, artificial intelligence, development of relevant educational courses, training methods, economic and cost problems and other items of theoretical and practical interest.

\section{Price information}

is available at: http://journals.cambridge.org/rob

\section{Free email alerts}

Keep up-to-date with new material - sign up at http://journals.cambridge.org/rob-alerts

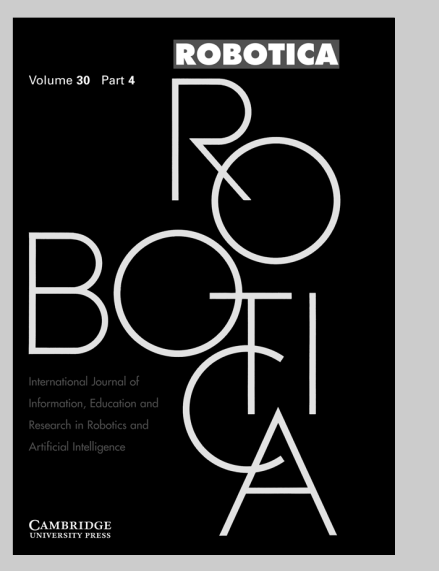

Robotica

is available online at:

http://journals.cambridge.org/rob

To subscribe contact

Customer Services

\section{in Cambridge:}

Phone +44 (0)1223 326070

Fax +44 (0)1223 325150

Email journals@cambridge.org

\section{in New York:}

Phone +1 (845) 3537500

Fax +1 (845) 3534141

Email

subscriptions_newyork@cambridge.org 


\section{The knowledge engineering review}

\section{Notes for Contributors}

\section{Editorial policy}

The Knowledge Engineering Review has been established to provide a general source of information and analysis in all areas relevant to research and development in knowledge based systems and applied artificial intelligence. The editors wish to encourage careful preparation of original papers analysing developments in the field. In particular we wish to see tutorial and survey articles, and commentary, criticism and debate. Primary research papers on specialised technical topics are unlikely to be appropriate but research papers on broad topics such as development methodology or general evaluations of tools and techniques, are of interest. Descriptions of specific projects or particular computer systems will be considered if their presentation draws out general issues in the design, implementation or impact of knowledge based systems.

\section{Submission of manuscripts}

Contributions for publication should be submitted as PDF files in an email attachment to either Professor Simon Parsons, Department of Computer and Information Science, Brooklyn College, City University of New York (parsons@sci.brooklyn.cuny. edu) or to Dr Peter McBurney, Department of Computer Science, University of Liverpool, UK (mcburney@liverpool.ac.uk). Submission implies that the manuscript has not been published previously, nor currently submitted for publication elsewhere. Upon acceptance of a manuscript, the author will be asked to transfer copyright to the publisher.

All contributions, whether articles, correspondence or reviews, must be sent in electronic form. Authors are encouraged to provide the final version of the contribution in LaTeX, TeX, or Word format.

Authors using LaTeX should ideally use the KER LaTeX style file which can be obtained using anonymous FTP from the internet address ftp://ftp.cambridge.org/pub/texarchive/journals/latex/ker-cls. In case of difficulties obtaining these files, there is a help-line available via e-mail; please contact texline@cup.cam.ac.uk. Tables and figures should be embedded in the article in the usual way, with figures in .eps form, which should be also supplied as separate files.

Contributions should follow the general style of papers in recent issues of The Knowledge Engineering Review. The author is invited to nominate up to five possible referees, who will not necessarily be used.

Articles must be accompanied by a brief, informative rather than indicative, abstract.

If you are not using the ker.cls file, then please adopt the following layout rules. Headings should be set out clearly but not underlined. Primary headings should be in lower case, at margin, with Arabic numeral; subheadings should be numbered 2.a., 2.b., etc., and tertiary headings, 2.a.1., 2.a.2. No cross-references should be given by page number, but 'above' and 'below' should be used with the section specified, e.g. Section 2.a.2. The SI system of units should be used. The author should mark in the margin of the manuscript where figures and tables may be inserted. References to points in larger works should, where possible, quote the page reference, e.g. Ager, 1981, p. 102.

Tables should be typed with double-line spacing on sheets separate from the running text. Each table must have a caption that will make the data in the table intelligible without reference to the text.

Illustrations should be drafted for reproduction as full page $(148 \mathrm{~mm})$ width. Originals should normally be drawn at twice final area and must be sent in a flat package; larger drawings may delay publication. Lettering should be of a size so that when reduces the smallest lower-case letters will not be less than about $1 \mathrm{~mm}$. Avoid gross disparities in lettering size on a drawing. Duplicates of illustrations should be sent, and may be prints or, preferably, photocopies reduced to final size. Illustrations in the text, both line drawings and photographs for halftone reproductions, will be referred to as figures (Fig. 2, 2a, etc.). Folding plates will not be accepted. Figures composed of photographs should be glossy prints presented at publication scale. Figure captions must be typed with double-line spacing on sheets separate from the running text.

The preferred graphics package is Freehand 5 but files from many others can be accepted. Please indicate clearly the file format (e.g. TIFF, EPS, DCS, Freehand etc), computer operating system and graphics software used for originating the artwork files. The typefaces used in electronic artwork supplied should be restricted to Monotype, Adobe and Bitstream font libraries. Illustrations should be supplied as EPS files and never as Postscript files, or as the native format files from the graphics package used. They should be accompanied by laser proofs with the name and version number of the graphics package used, and also the names of the fonts used.

\section{References}

The accuracy of references is the responsibility of authors. References must be double-spaced and spelt out in full, e.g:

Gale, W A, ed 1986. Artificial Intelligence and Statistics, Reading, Massachusetts: Addison-Wesley.

Pearl, J 1984. Heuristics. Intelligent search strategies for problem solving, Reading, Massachusetts: Addison-Wesley.

Tie-Cheng Wang and Bledsoe, W W, 1987. "Hierarchical deduction" Journal of Automated Reasoning 3 (1) pp 1-34.

Pau, L F, 1986. "Survey of expert systems for fault detection, test generation and maintenance" Expert Systems, 3 (2) pp 100-111.

Unpublished work should normally be referred to in the text parentheses as, for example, 'private communication' or 'unpub. Ph.D. thesis, Univ. London, 1988', and not included in the reference list unless in the press.

\section{Proof Reading:}

Typographical or factual errors only may be changed at proof stage. The publisher reserves the right to charge authors for correction of non-typographical errors. No page charge is made.

\section{Offprints:}

No paper offprints are provided, but the corresponding author will be sent the pdf of the published article. Print offprints may be purchased at extra cost at proof stage.

(C) Cambridge University Press 2013

(Revised 11 June 2010) 


\section{The knowledge engineering review}

VOLUME 28 NUMBER 2 JUNE 2013

\section{Contents}

Preface to special issue on Knowledge Engineering for Planning and

Scheduling

ROMAN BARTÁK, SIMONE FRATINI and THOMAS LEO MCCLUSKEY

On the automatic compilation of e-learning models to planning

ANTONIO GARRIDO, SUSANA FERNÁNDEZ, LLUVIA MORALES,

EVA ONAINDÍA, DANIEL BORRAJO and LUIS CASTILLO

The PORSCE II framework: using Al planning for automated Semantic

Web service composition

OURANIA HATZI, DIMITRIS VRAKAS, NICK BASSILIADES,

DIMOSTHENIS ANAGNOSTOPOULOS and IOANNIS VLAHAVAS

Using automated planning for improving data mining processes

SUSANA FERNÁNDEZ, TOMÁS DE LA ROSA,

FERNANDO FERNÁNDEZ, RUBÉN SUÁREZ, JAVIER ORTIZ,

DANIEL BORRAJO and DAVID MANZANO

From business process models to hierarchical task network planning domains

ARTURO GONZÁLEZ-FERRER, JUAN FERNÁNDEZ-OLIVARES

and LUIS CASTILLO

Acquiring planning domain models using LOCM

STEPHEN N. CRESSWELL, THOMAS L. MCCLUSKEY

and MARGARET M. WEST

itSIMPLE: towards an integrated design system for real planning applications

TIAGO S. VAQUERO, JOSÉ R. SILVA, FLAVIO TONIDANDEL

and J. CHRISTOPHER BECK 